(2) Open Access Full Text Article

\title{
Comparison between treadmill and bicycle ergometer exercise tests in mild-to-moderate hypertensive Nigerians
}

This article was published in the following Dove Press journal: Integrated Blood Pressure Control

II August 2015

Number of times this article has been viewed

\author{
Olugbenga $\bigcirc$ Abiodun \\ Michael O Balogun \\ Anthony O Akintomide \\ Rasaaq A Adebayo \\ Olufemi E Ajayi \\ Suraj A Ogunyemi \\ Valentine N Amadi \\ Victor O Adeyeye \\ Cardiology Unit, Department \\ of Medicine, Obafemi Awolowo \\ University Teaching Hospitals \\ Complex (OAUTHC), Ile-Ife, Osun \\ state, Nigeria
}

Background: Comparative cardiovascular responses to treadmill and bicycle ergometer (bike) exercise tests in hypertensive Nigerians are not known. This study compared cardiovascular responses to the two modes of exercise testing in hypertensives using maximal exercise protocols.

Methods: One hundred and ten male subjects with mild-to-moderate hypertension underwent maximal treadmill and bike test one after the other at a single visit in a simple random manner. Paired-sampled $t$-test was used to compare responses to both exercise tests while chi-squared test was used to compare categorical variables.

Results: The maximal heart rate $(P<0.001)$, peak systolic blood pressure $(P=0.02)$, rate pressure product $(P<0.001)$, peak oxygen uptake $(P<0.001)$, and exercise capacity $(P<0.001)$ in metabolic equivalents were significantly higher on the treadmill than on the bike.

Conclusion: Higher cardiovascular responses on treadmill in Nigerian male hypertensives in this study, similar to findings in non-hypertensives and non-Nigerians in earlier studies, suggest that treadmill may be of better diagnostic utility in our population.

Keywords: maximal exercise, treadmill, bicycle ergometer, hypertension, Nigerians

\section{Introduction}

Hypertension remains a common cause of morbidity and mortality worldwide. ${ }^{1}$ Studies have shown that low-to-moderate intensities of exercise $(35 \%-79 \%$ of age-predicted maximum heart rate) not only can reduce systolic blood pressure (SBP) by $3.5-10.5 \mathrm{mmHg}$ but can also decrease cardiovascular (CV) morbidity and mortality. ${ }^{2}$ The mechanism through which exercise exerts these effects is not completely understood, but it appears to be largely related to vascular regulation, especially, reduction in total peripheral resistance, as a result of neurohormonal, vascular, and genetic adaptations. Other proposed mechanisms include inflammation as well as lipid, insulin, and glucose metabolism. ${ }^{3}$

Hypertensive patients will benefit from performing low-to-moderate intensity dynamic exercises, such as walking, running, and cycling on a daily basis. ${ }^{3}$ Exercise takes several forms, but the two most common modes of formal exercise testing are the treadmill walking or running and bicycle ergometry. It is also important to diagnose abnormal CV responses that may not be present at rest, which may lead to morbidity and mortality. ${ }^{4,5}$ Studies on the comparison of exercise responses on treadmill and bike have been largely among healthy subjects, coronary artery disease (CAD) and heart failure patients. ${ }^{5}$ These studies have been extrapolated to hypertensives because there are no universally accepted guidelines on exercise testing directed specifically toward assessing and managing hypertensive patients. ${ }^{6}$
Correspondence: Olugbenga O Abiodun Cardiology Unit, Department of Medicine, Obafemi Awolowo University Teaching Hospitals Complex (OAUTHC), Ile-Ife, Osun state, Nigeria Email philabiodun@yahoo.com submit your manuscript | www.dovepress.com Dovepress 
Exercise testing is also indicated for individuals with multiple $\mathrm{CV}$ risk factors and asymptomatic individuals above 40 years who intend to start an exercise program to determine fitness. ${ }^{7}$ Many hypertensives fit into this picture, and are at increased risk of sudden cardiac death if they engage in strenuous exercise. ${ }^{8}$ In our environment, hypertension is the commonest cause of sudden cardiac death. ${ }^{9}$ We hypothesize that in our environment, treadmill and bike exercises will be equally useful in eliciting cardiac and vascular responses, abnormalities of which may predispose patients to sudden death. To test this hypothesis, we compared CV responses to the two modes of exercise tests.

\section{Subjects and methods}

This study was carried out at the cardiac care unit of Obafemi Awolowo University Teaching Hospitals Complex (OAUTHC), Ile-Ife, Osun State, Nigeria. One hundred and ten male subjects with mild-to-moderate hypertension ${ }^{10}$ diagnosed at the cardiology clinic were consecutively recruited for the study. They had routine history taking, physical examination, biochemical tests, 12-lead resting electrocardiography, and transthoracic echocardiography. Subjects were on diuretics, calcium channel blockers (dihydropyridines), angiotensin converting enzyme inhibitors, beta blockers, angiotensin receptor blockers, and centrally acting antihypertensives, either alone or in combinations.

Subjects with heart failure, severe hypertension, secondary hypertension, contraindications to exercise testing, trained athletes, and conditions that may impair exercise testing were excluded from this study. Very few female subjects volunteered for the study, so males alone were used.

They were then exercised on a bike (Lode, Groningen, the Netherlands) and treadmill (Schiller CS-200, Schiller AG, Baar, Switzerland) during one visit. To control for a potential exercise mode order effect, subjects were assigned an exercise mode sequence in a random manner. Subjects commenced the second mode after they had rested well (20-30 minutes) and when the heart rate (HR) and blood pressure (BP) had returned to within \pm 5 of resting values. ${ }^{11}$

Ethical clearance for the study was obtained from the Ethics and Research Committee of the Obafemi Awolowo University Teaching Hospitals Complex (Ile-Ife, Nigeria) and participants gave informed consent.

The exercise laboratory and equipment conformed to the standard specifications for exercise testing. ${ }^{12}$ A GE cardioserve defibrillator (GE Healthcare Europe GmbH, Freiburg, Germany) equipped with a portable electrocardiography monitor and emergency care medications were provided. Subjects had a demonstration and practiced treadmill walking and leg cycling.

Astrand maximal cycle test protocol was used for bike test while the Bruce protocol was used for treadmill test. ${ }^{5,13}$ Subjects commenced exercise at $50 \mathrm{~W}$ workload after the bike height had been adjusted. The work load was increased by $25 \mathrm{~W}$ every 3 minutes and the pedal speed remained constant throughout the exercise at 50 revolutions per minute (rpm). ${ }^{5}$ The treadmill was conducted in six stages, each stage lasting 3 minutes at a progressive speed of 2.74, 4.02, $5.47,6.76,8.05 \mathrm{kmph}$, to $8.85 \mathrm{kmph}$ and at a progressively increased gradient of $2 \%$ per stage from $10 \% .5,13$

Subjects continued to exercise until completion of exercise or till an indication for cessation of exercise was reached, such as request that exercise be terminated, development of chest pain, undue breathlessness, dizziness or fainting, SBP $>250 \mathrm{mmHg}$, a drop in the pre-test $\mathrm{SBP}>10 \mathrm{mmHg}$, and electrocardiographic changes necessitating termination of exercise. ${ }^{7}$

The HR and BP were monitored and recorded preexercise, during the last 30 seconds of each stage of exercise, and 1,3, and 6 minutes postexercise. The BP was measured using a mercury sphygmomanometer (Accuson, Kris-Alloy, England) in the upright position while the HR was displayed on the digital HR meter.

The American College of Sports Medicine (ACSM) formula ${ }^{14}$ was used to calculate peak oxygen uptake $\left(\mathrm{VO}_{2}\right)$ for bicycle ergometry: power in $\mathrm{kpm} \times 1.8$ /body weight in $\mathrm{kg}+7 . \mathrm{VO}_{2}$ was estimated using the ACSM formula ${ }^{14}$ for treadmill (TM) exercise:

$$
(0.1 \times \text { speed })+(1.8 \times \text { speed } \times \text { grade })+3.5 \text {. }
$$

Exercise capacity (EC) for both exercise modes was calculated using the following formula:

$\mathrm{EC}$ in metabolic equivalents $(\mathrm{METs})=\mathrm{VO}_{2} \div 3.5 .^{14}$

\section{Data analysis}

Data was analyzed using the SPSS version 16 software. Categorical variables were expressed as proportions and percentages while continuous variables were expressed as means \pm standard deviation or as ranges. Statistical analysis was by paired-sampled $t$-test to compare maximal heart rate (MHR), peak systolic blood pressure (PSBP), rate pressure product (RPP), and maximal EC on treadmill and bike exercises. Chi-squared test was used to compare categorical variables. $P<0.05$ was taken as statistically significant. 


\section{Results}

The descriptive characteristics of the study participants are shown in Table 1. The mean age of patients was 43.7 \pm 9.27 years (range between 21 and 60 years), with a mean duration of hypertension (from the time of diagnosis) being $51.0 \pm 4.88$ months.

Table 2 shows the comparison of $\mathrm{CV}$ responses to the two exercise modalities in the study population. Subjects significantly exercised longer on bike (558.6 $\pm 90.84 \mathrm{~s})$ than on the treadmill (508.8 $\pm 79.80 \mathrm{~s})(P=0.002)$. The MHR $(156.4 \pm 19.48$ bpm) and MHR expressed as percentage of age predicted (\%THR) $(88.3 \% \pm 9.13 \%)$ on treadmill were significantly higher than on bike (140.5 $\pm 15.25 \mathrm{bpm}$ and $78.8 \% \pm 10.49 \%)$ $(P<0.001)$. Also, subjects achieved significantly higher PSBP of $205.3 \pm 24.92 \mathrm{mmHg}$ on treadmill compared with $199.5 \pm 24.96 \mathrm{mmHg}$ on bike $(P=0.02)$.

In these subjects, the RPP was significantly higher for mode of exercise on treadmill at $322.0 \pm 61.27 \mathrm{mmHg} \cdot \mathrm{bpm}$ $\times 10^{-2}$ compared to $280.3 \pm 46.11 \mathrm{mmHg} \cdot \mathrm{bpm} \times 10^{-2}$ on bike $(P<0.001)$.

The peak oxygen uptake $\left(\mathrm{VO}_{2} \max \right)(69.3 \pm 18.59 \mathrm{~mL} / \mathrm{min} /$ $\mathrm{kg}$ on treadmill vs $21.8 \pm 4.73 \mathrm{~mL} / \mathrm{min} / \mathrm{kg}$ on bike $[P<0.001])$ and EC (19.8 \pm 5.31 METs on treadmill compared with $6.2 \pm 1.35$ METs $[P<0.001]$ on bike) were all significantly higher on treadmill.

The mean heart rate recovery at 1 minute postexercise $\left(\mathrm{HRR}^{1}\right)$ did not show any difference on the treadmill (29.4 $\pm 17.44 \mathrm{bpm})$ compared with bike $(29.2 \pm 13.49 \mathrm{bpm})$ $(P=0.93)$. Twelve subjects $(10.9 \%)$ had abnormal heart rate

Table I Descriptive characteristics of the study population

\begin{tabular}{ll}
\hline Variables & Mean \pm SD \\
\hline Age (years) & $43.7 \pm 9.27$ \\
DOH (months) & $51.0 \pm 4.88$ \\
PA, $\mathrm{n}(\%)$ & $34(30.9 \%)$ \\
BMI $\left(\mathrm{kg} / \mathrm{m}^{2}\right)$ & $26.3 \pm 4.66$ \\
Family history of hypertension & $54(49.1 \%)$ \\
rHR $(\mathrm{b} / \mathrm{m})$ & $79.8 \pm 12.00$ \\
rSBP $(\mathrm{mmHg})$ & $126.5 \pm 15.10$ \\
rDBP $(\mathrm{mmHg})$ & $85.0 \pm 10.50$ \\
RBS $(\mathrm{mmol} / \mathrm{L})$ & $5.3 \pm 0.82$ \\
TC $(\mathrm{mmol} / \mathrm{L})$ & $5.6 \pm 0.66$ \\
LVH $(\mathrm{ECG})$ & $48(43.6 \%)$ \\
LVMI $\left(\mathrm{g} / \mathrm{m}^{2}\right)$ & $105.9 \pm 16.60$ \\
Medications, $\mathrm{n}(\%)$ & $90(81.8 \%)$ \\
\hline
\end{tabular}

Notes: Unless otherwise stated, results are expressed in mean \pm standard deviation; $\mathrm{n}$ is expressed in frequency.

Abbreviations: SD, standard deviation; $\mathrm{DOH}$, duration of hypertension from time of diagnosis; PA, proportion of subjects physically active; BMI, body mass index; rHR, resting heart rate; rSBP, resting systolic blood pressure; rDBP, resting diastolic blood pressure; RBS, random blood sugar; TC, total cholesterol; LVH, left ventricular hypertrophy; LVMI, left ventricular mass index.
Table 2 Comparison of exercise parameters in mild-to-moderate hypertensive subjects

\begin{tabular}{|c|c|c|c|}
\hline Variable & Treadmill & $\begin{array}{l}\text { Bicycle } \\
\text { ergometer }\end{array}$ & $P$-value \\
\hline DOE (secs) & $508.8 \pm 79.80$ & $558.6 \pm 90.84$ & $0.002 *$ \\
\hline rHR (bpm) & $84.3 \pm 14.30$ & $81.5 \pm 13.09$ & 0.07 \\
\hline rSBP $(\mathrm{mmHg})$ & $126.8 \pm 15.48$ & $125.7 \pm 15.56$ & 0.45 \\
\hline $\mathrm{rDBP}(\mathrm{mmHg})$ & $86.8 \pm 10.50$ & $85.6 \pm 10.58$ & 0.09 \\
\hline MHR (bpm) & $156.4 \pm 19.48$ & $140.5 \pm \mid 5.25$ & $<0.00 I^{* *}$ \\
\hline \%THR (\%) & $88.3 \pm 9.13$ & $78.8 \pm 10.49$ & $<0.00 I^{* *}$ \\
\hline PSBP $(\mathrm{mmHg})$ & $205.3 \pm 24.92$ & $199.5 \pm 24.96$ & $0.02 *$ \\
\hline PDBP $(\mathrm{mmHg})$ & $72.9 \pm 12.61$ & $72.8 \pm 11.77$ & 0.93 \\
\hline RPP $\left(\mathrm{mmHg} \cdot \mathrm{bpm} \times 10^{-2}\right)$ & $322.0 \pm 61.27$ & $280.3 \pm 46.11$ & $<0.00 I^{* *}$ \\
\hline $\mathrm{VO}_{2}(\mathrm{~mL} / \mathrm{min} / \mathrm{kg})$ & $69.3 \pm 18.59$ & $21.8 \pm 4.73$ & $<0.00 I^{* *}$ \\
\hline EC (METs) & $|9.8 \pm 5.3|$ & $6.2 \pm 1.35$ & $<0.00 I^{* *}$ \\
\hline HRR' (bpm) & $29.4 \pm 17.44$ & $29.2 \pm 13.49$ & 0.93 \\
\hline AHRR', n (\%) & $12(10.9 \%)$ & $12(10.9 \%)$ & 0.24 \\
\hline
\end{tabular}

Notes: Unless otherwise stated, values are expressed as mean \pm standard deviation. *Statistically significant with $P$-value $<0.05$; **statistically significant with $P$-value $<0.001$.

Abbreviations: DOE, duration of exercise; rHR, resting heart rate; rSBP, resting systolic blood pressure; rDBP, resting diastolic blood pressure; MHR, maximal heart rate; \%THR, maximum heart rate expressed as percentage of age predicted; PSBP, peak systolic blood pressure; PDBP, peak diastolic blood pressure; RPP, rate pressure product; $\mathrm{VO}_{2}$, peak oxygen uptake; EC, exercise capacity; METs, metabolic equivalents; HRR', heart rate recovery at I minute postexercise; AHRR', abnormal heart rate recovery at I minute postexercise.

recovery at 1 minute $\left(\mathrm{AHRR}^{1}\right)$ postexercise during both exercises.

Table 3 shows exaggerated BP response (EBPR) among subjects. The occurrence of EBPR during both exercise tests was similar.

\section{Discussion}

Exercise test responses on treadmill and bike have been compared in normal subjects and CAD patients, and extrapolations have then been made to hypertensives. ${ }^{5,6}$ This work showed a significantly higher MHR, RPP, PSBP, and $\mathrm{VO}_{2}$ max during maximal treadmill exercise compared with bike in these hypertensive Nigerian subjects. This agrees with previous work in the same exercise laboratory with similar exercise protocol but in healthy young male subjects. ${ }^{5}$ In India, Kisan et a $1^{15}$ using submaximal exercise protocols exercised 21 normal male subjects and found significantly higher PSBP of $144.1 \pm 4.0 \mathrm{mmHg}$ and MHR of $161.7 \pm 14.2 \mathrm{bpm}$ during treadmill exercise compared with $127.1 \pm 6 \mathrm{mmHg}$ and

Table 3 Exaggerated blood pressure response among subjects

\begin{tabular}{llll}
\hline Test & Treadmill, $\mathbf{n}(\%)$ & Ergometer, $\mathbf{n}(\%)$ & P-value \\
\hline EBPR & $22(20 \%)$ & $21(19.1 \%)$ & 0.87 \\
NEBPR & $88(80 \%)$ & $89(80.9 \%)$ & 0.87 \\
\hline
\end{tabular}

Abbreviations: EBPR, exaggerated blood pressure response (SBP $>230 \mathrm{mmHg}$ ); NEBPR, no exaggerated blood pressure response; SBP, systolic blood pressure. 
129.9 $\pm 9.3 \mathrm{bpm}$, respectively, on the bike. Similarly, using maximal protocols, others have reported higher MHR ${ }^{16-18}$ and $\mathrm{VO}_{2} \max ^{18-21}$ on the treadmill. While Wicks et $\mathrm{al}^{18}$ reported higher MHR and $\mathrm{VO}_{2}$ on the treadmill than the bike, they did not find a difference in the RPP between the two tests because of higher SBP on the bike, in contrast to our study. This is similar to the work by Kim et $\mathrm{al}^{22}$ who exercised 15 apparently healthy Koreans. They found higher PSBP and RPP but lower MHR and $\mathrm{VO}_{2}$ max on the bike compared with the treadmill. The higher PSBP by Kim et $\mathrm{al}^{22}$ may be the result of higher exercise intensity from a pedaling cadence of $70 \mathrm{rpm}$ compared to $50 \mathrm{rpm}$ used in our study, leading to greater upper body isometric contraction and lower body intramuscular tension. ${ }^{11}$ Also, with our sample size of 110 subjects, compared to 15 by Kim et al, ${ }^{22}$ our findings are likely to be more reliable.

The higher CV responses on the treadmill in this study may be the result of large interstage increments in work and increased oxygen costs of running from stage III. The treadmill therefore imposes more hemodynamic stress on the myocardium than the bike. Because of higher MHR on the treadmill, the treadmill has been reported to be more sensitive in diagnosing CAD than the bike test. ${ }^{17}$ In this work, direct estimation of $\mathrm{VO}_{2}$ max was not done because it requires expensive and time-consuming measuring equipment. However, an indirect method using ACSM formula was used and is considered an acceptable predictor of $\mathrm{VO}_{2}$ max. ${ }^{14,23}$

In an earlier study in normal subjects from the same exercise laboratory, subjects exercised significantly longer on treadmill than on bike. ${ }^{5}$ However, in this hypertensive population, we observed that the subjects exercised longer on bike than treadmill. This difference may be explained by the familiarity of the hypertensive population with cycle riding as most of them reported to have ridden the bicycle well in the past. Also, exhaustion significantly limited treadmill exercise in this study than it limited cycle ergometry, and this may have also contributed to the longer duration on bike.

$\mathrm{AHRR}^{1}$ refers to a relatively slow deceleration of $\mathrm{HR}$ following exercise cessation. It is the abnormal difference of $<12$ bpm between the MHR and HR a minute after cessation of exercise. This type of response reflects decreased vagal tone and is associated with increased mortality. ${ }^{24}$ It has been suggested as a useful addition to the criteria currently used to assess exercise stress test results. ${ }^{25}$ This study showed no difference in the $\mathrm{AHRR}^{1}$ in hypertensives during the two exercise tests. Hence, both exercise tests can be used to assess prognosis of hypertensives using AHRR ${ }^{1}$.
Abnormal BP responses to exercise have diagnostic and prognostic values in normotensives. ${ }^{26,27}$ In hypertensive subjects, BP during exercise greater than 200-230 mmHg has been found to be associated with mortality from $\mathrm{CV}$ disease. ${ }^{28-30}$ Mundal et $\mathrm{al}^{28}$ reported findings linking an exaggerated increase in SBP greater than $200 \mathrm{mmHg}$ at submaximal exercise with increased mortality in hypertensive patients from myocardial infarction, cerebral stroke, and sudden death. Also, Filipovsky et $\mathrm{al}^{29}$ showed that the risk of death from $\mathrm{CV}$ disease increased by $60 \%$ in subjects whose SBP was greater than $230 \mathrm{mmHg}$. At maximal treadmill workload, Balogun and Ladipo ${ }^{30}$ reported an EBPR prevalence of 45\% among hypertensive males. The mechanism through which EBPR increases CV morbidity and mortality has not been widely studied. Chang et al, ${ }^{31}$ however, suggested that endothelial dysfunction and impaired vasodilatory capacity of the peripheral vasculature may be the mechanisms. The prevalence of EBPR in this study during treadmill and cycle ergometry was similar at $20 \%$ and $19.1 \%$, respectively, but lower than previously observed. This may be the result of improved BP control from the use of more effective antihypertensive medications either singly or in combinations, and improved awareness of the dangers of HBP now. In this study, most of the patients were on diuretics, calcium channel blockers, and angiotensin converting enzyme inhibitors. Hypotension during or after exercise is usually seen in subjects with myocardial ischemia, cardiomyopathy, cardiac arrhythmias, vasovagal reactions, left ventricular outflow tract obstruction, hypovolemia, and prolonged vigorous exercise. ${ }^{13}$ None of our subjects had hypotension during or after exercise. Also, none had life-threatening exercise-induced arrhythmias.

\section{Limitation of study}

This study can be considered a male study, and responses may not be generalized to females.

\section{Conclusion}

This study shows that overall, CV responses are higher on treadmill than on the bike in mild-to-moderate hypertensive Nigerian male patients. This suggests that treadmill may be of better diagnostic utility in mild-to-moderate hypertensive patients. We also suggest that either exercise test is safe to assess mild-to-moderate hypertensive patients prior to starting an exercise program. Follow-up of patients with abnormal $\mathrm{CV}$ responses in this study is imperative to ascertain their impact on CV morbidity and mortality. Many individuals cannot afford personal or communal exercise machines for their own exercise program. Efforts should be made by the 
government to put in place policies and infrastructures that will promote increased physical activity in communities and workplace.

\section{Disclosure}

The authors report no conflicts of interest in this work.

\section{References}

1. Lawes CMM, Hoorn SV, Rodgers A. Global burden of blood pressurerelated disease. Lancet. 2008;371(9623):1513-1518.

2. Kokkinos P, Myers J. Exercise and physical activity: clinical outcomes and applications. Circulation. 2010;122:1637-1648.

3. Dangardt FJ, McKenna WJ, Lüscher TF, Deanfield JE. Exercise: friend or foe? Nat Rev Cardiol. 2013;10(9):495-507.

4. Fuster V, O'Rourke RA, Walsh R, et al. ECG Exercise Testing, Hurst's The Heart, 12th ed. New York: McGraw-Hill Medical; 2007.

5. Balogun MO, Sulyman BO, Akinwusi PO. A comparison of the cardiovascular responses to treadmill and bicycle ergometer exercise in healthy male Nigerians. Afr J Med Med Sci. 1997;26:27-30.

6. Lim PO, MacFadyen RJ, Clarkson PBM, MacDonald TM. Impaired exercise tolerance in hypertensive patients. Ann Intern Med. 1996; 124(1):41-55.

7. Gibbons RJ, Balady GJ, Bricker JT, et al. American Heart Association (AHA) 2002 guideline update for exercise testing. Summary article: A report of the American College of Cardiology (ACC)/AHA Task Force on Practice Guidelines. J Am Coll Cardiol. 2002;106:1883-1892.

8. Thompson PD, Franklin BA, Balady GJ, Blair SN, Corrado D, Estes NA. Exercise and acute cardiovascular events placing the risks into perspective: a scientific statement from the American Heart Association Council on Nutrition, Physical Activity, and Metabolism and the Council on Clinical Cardiology. Circulation. 2007;115(17): 2358-2368.

9. Ogunlade O. Sudden cardiac death in Nigeria: A health challenge. Int $J$ Health Res. 2011;4(4):163-168.

10. Guidelines Sub-Committee. 1999 World Health Organization/ International Society of Hypertension Guidelines for the management of hypertension. J Hypertens. 1999;17:151-183.

11. Reed J. Blood pressure responses of sedentary African American women during cycle and treadmill exercise. Ethnic Dis. 2007;17:59-64.

12. Myers J, Arena R, Franklin B, et al. Guidelines for clinical exercise testing laboratories. Circulation. 2009;119:3144-3161.

13. Chaitman BR. Exercise stress testing. In: Bonow RO, Mann DL, Zipes DP, Libby P, editors. Braunwald's Heart Disease. A Textbook of Cardiovascular Medicine. 9th ed. Philadelphia: Elsevier Saunders; 2012:168-192.

14. American College of Sports Medicine Guidelines for Exercise Testing and prescription. 8th ed. Philadelphia: Lippincott Williams \& Wilkins; 2010.
15. Kisan R, Kisan SR, Anitha OR, Chandrakala SP. Treadmill and bicycle ergometer exercise: cardiovascular response comparison. Glob J Med Res. 2012;12(5).

16. Buchfuhrer MJ, Hansen JE, Robinson TE, et al. Optimizing the exercise protocol for cardiopulmonary assessment. J Appl Physiol. 1983;55:1558-1564

17. Hambrecht R, Schuler GC, Muth T, et al. Greater diagnostic sensitivity of treadmill versus cycle exercise testing of asymptomatic men with coronary artery disease. Am J Cardiol. 1992;70:141-146.

18. Wicks JR, Sutton JR, Oldridge NB, et al. Comparison of the electrocardiographic changes induced by maximum exercise testing with treadmill and cycle ergometer. Circulation. 1978;57:1066-1069.

19. Myers J, Buchanan N, Walsh D, et al. Comparison of the ramp versus standard exercise protocols. J Am Coll Cardiol. 1991;17:1334-1342.

20. Basset FA, Boulay MR. Specificity of treadmill and cycle ergometer tests in triathletes, runners and cyclists. Eur J Appl Physiol. 2000;81: 214-221.

21. Maeder M, Wolber T, Atefy R, Gadza M, Ammann P, Myers J. Impact of the exercise mode on exercise capacity. Bicycle testing revisited. Chest. 2005;128:2804-2811.

22. Kim YJ, Chun H, Kim C. Exaggerated response of systolic blood pressure to cycle ergometer. Ann Rehabil Med. 2013;37(3):364-372.

23. Kokkinos P, Myers J, Kokkinos JP, et al. Exercise capacity and mortality in black and white men. Circulation. 2008;117:614-622.

24. Adabag AS, Grandits GA, Prineas RJ, Crow RS, Bloomfield HE, Neaton JD. Relation of the heart rate parameters during exercise test to sudden death and all-cause mortality in asymptomatic men. Am J Cardiol. 2008;101:1437-1443.

25. Yawn BP, Ammar KA, Thomas R, Wollan PC. Test-retest reproducibility of heart rate recovery after treadmill exercise. Ann Fam Med. 2003;1(4):236-241.

26. Lewis GD, Gona P, Larson MG, et al. Exercise blood pressure and the risk of incident cardiovascular disease (from the Framingham Heart Study). Am J Cardiol. 2008;101:1614-1620.

27. Matthews CE, Pate RR, Jackson KL, et al. Exaggerated blood pressure response to dynamic exercise and risk of future hypertension. J Clin Epidemiol. 1998;51:29-35.

28. Mundal R, Kjeldsen SE, Sandvik L, Erikssen G, Thaulow E, Erikssen J. Exercise blood pressure predicts cardiovascular mortality in middleaged men. Hypertension. 1994;24:56-62.

29. Filipovsky J, Ducimetiere P, Safar ME. Prognostic significance of exercise blood pressure and heart rate in middle-aged men. Hypertension. 1992;20:333-339.

30. Balogun MO, Ladipo GOA. Cardiovascular responses to exercise in essential hypertension. West Afr J Med. 1990;9:272-278.

31. Chang HJ, Chung J, Choi SY, et al. Endothelial dysfunction in patients with exaggerated blood pressure response during treadmill test. Clin Cardiol. 2004;27(7):421-425.
Integrated Blood Pressure Control

\section{Publish your work in this journal}

Integrated Blood Pressure Control is an international, peer-reviewed open-access journal focusing on the integrated approach to managing hypertension and risk reduction. Treating the patient and comorbidities together with diet and lifestyle modification and optimizing healthcare resources through a multidisciplinary team approach constitute key

\section{Dovepress}

features of the journal. This journal is indexed on American Chemical Society's Chemical Abstracts Service (CAS). The manuscript management system is completely online and includes a very quick and fair peerreview system, which is all easy to use. Visit http://www.dovepress.com/ testimonials.php to read real quotes from published authors. 